\title{
Gestionar los odios para obtener la paz: paradojas de la construcción de la paz en Colombia*
}

\author{
Managing hatred to achieve peace: \\ paradoxes of constructing peace in Colombia
}

\author{
JOHN JAIRO URIBE SARMIENTO** / MELANNIE ROMERO*** \\ MARÍA CAMILA MEJÍA**** / MARÍA DEL PILAR SALAMANCA*****
}

\begin{abstract}
Colombian attitudes are analyzed in relation to the peace treaty signed between the government and the Colombian Revolutionary Armed Forced (Fuerzas Armadas Revolucionarias de Colombia - FARC). For this, related phenomena are examined regarding the plebiscite through which such an agreement was approved or refused: campaign strategies for or against, opinion polls regarding key topics (political participation, coexisting with former combatants), and focus groups discussions. The main argument is that management of hatred and fear have led to a foundation on which to build peace in the country.
\end{abstract}

Key words: culture of peace in Colombia, social representations, FARC, peace agreement

\begin{abstract}
Resumen
Se analizan las actitudes de los colombianos frente al acuerdo de paz firmado entre el gobierno y las Fuerzas Armadas Revolucionarias de Colombia (FARC). Para ello se examinan fenómenos relacionados con el plebiscito mediante el cual los ciudadanos aprobaron o no dicho acuerdo: estrategias de campaña en favor o en contra, encuestas de opinión sobre temas cruciales (participación política, convivencia con excombatientes) y discusiones en grupos focales. Se argumenta que la gestión de los odios y los miedos devino el eje para construir la paz en el país.
\end{abstract}

Palabras clave: cultura de paz en Colombia, representaciones sociales, FARC, acuerdos de paz

* Artículo recibido el 30/01/19 y aceptado el 22/05/19.

** Universidad de Ibagué, Colombia. Carrera 22 Calle 67 B, Av. Ambalá, Ibagué, Tolima, Colombia <john.uribe@unibague. edu.co>. ORCID: http://orcid.org/0000-0001-6816-0631.

*** Contraloría Municipal de Ibagué, a 2-121, Cl. 9 \#2-1, Ibagué, Tolima, Colombia <melannierove@gmail.com>.

**** Superintendencia de Industria y Comercio de Colombia. Carrera 13 núm. 27-00, pisos 1 y 3, Bogotá, Colombia.

***** Universidad de Ibagué, Colombia. Carrera 22 Calle 67 B, Av. Ambalá, Ibagué, Tolima, Colombia <pilar.salamanca@ unibague.edu.co>. ORCID: http://orcid.org/0000-0001-7403-1705. 


\section{Presentación}

Todos los que votan sí descansen en paz, estable y duradera

Tuit publicado por Héctor Cuesta durante las campañas en favor y en contra de refrendar el acuerdo de paz a través del plebiscito

$\mathrm{L}$ a construcción de la paz va más allá de la firma de unos acuerdos de desmovilización y participación política; en efecto, el fin de la violencia a través de un acuerdo, o incluso de una victoria militar, no significa el logro de la paz (Lambourne, 2004). Con todo, un escenario de posconflicto crea oportunidades que pueden ser aprovechadas para mejorar la situación de la población que ha vivido los estragos del conflicto armado. Las condiciones en las que se desarrolló un conflicto proyectan sus sombras en el proceso de paz. El presente artículo discute los imaginarios sobre la paz y el posconflicto (postacuerdo) en Colombia (específicamente en el departamento del Tolima) alrededor de dos ejes: 1) el rechazo a la participación política de la guerrilla que se reincorpora (las Fuerzas Armadas Revolucionarias de Colombia, FARC), como "castigo" ciudadano por su accionar violento y 2) la creación de un ambiente de tensión en el que se gestionan miedos y odios, incluso desde algunos promotores de la paz.

$\mathrm{El}$ artículo recoge los resultados del proyecto de investigación Observatorio Regional de Paz, financiado por la Universidad de Ibagué. En el marco de dicho proyecto se realizaron entrevistas, sondeos y grupos focales en varios municipios del departamento del Tolima (Chaparral, Lérida, Ibagué). Se emplean también los resultados de la encuesta de percepción ciudadana aplicada por el programa Ibagué Cómo Vamos. ${ }^{1}$ Además, se puso en marcha una estrategia de seguimiento a tuits publicados por diferentes actores sociales y políticos que jugaron un papel clave como promotores de campañas en favor o en contra de los acuerdos de finalización del conflicto entre las FARC y el gobierno colombiano.

En esta perspectiva, vale la pena decir que las FARC cuentan con una imagen negativa que responde tanto a la crueldad de sus actuaciones como a la imagen promovida por los medios de comunicación nacionales. En efecto, éstas se convirtieron en el enemigo del país a través de un proceso comunicativo que lideró el expresidente Uribe desde 2002 (López de la Roche, 2014; Bonilla, Rincón y Uribe, 2013). Ese año se rompieron las negociaciones entre el gobierno colombiano (encabezado por Andrés Pastrana) y la guerrilla. Paradójicamente, luego de cuatro años, esas negociaciones contribuyeron a fortalecer a todos los actores armados (grupos de autodefensa, guerrillas y, finalmente, las fuerzas militares): las FARC venían adelantando las llamadas pescas milagrosas, en las que secuestraban a quienes caían en retenes ilegales, todo ello como parte de una estrategia que pretendía cercar a Bogotá; las autodefensas disputaron los territorios que controlaban las guerrillas desarrollando acciones terroríficas como masacres, asesinatos selectivos y amenazas a líderes. Por su parte, las fuerzas militares recibieron un impulso a través del Plan Colombia firmado por Pastrana antes de terminar su mandato, y que capitalizó el gobierno de Uribe.

Esto contribuyó a que muchos ciudadanos se sintieran seguros para viajar por el país, pues las guerrillas debieron retirarse hacia zonas alejadas de los centros urbanos. En este contexto, la retórica presidencial no sólo destacó los logros obtenidos, sino que sirvió para promover una visión particular de la historia del país, de sus problemas, de su identidad. Dicha retórica se concentró en el odio contra el adversario (López de la Roche, 2014), de modo que quien no estuviera alineado con las opiniones del presidente era considerado aliado del enemigo. Puede afirmarse que esta estrategia comunicativa no sólo contribuyó a generar un ambiente de apoyo a las fuerzas armadas legales (aspecto clave para su relativo éxito militar), sino que se desarrolló como una herramienta de gestión de lo social: los odios y los miedos se convirtieron en vectores ordenadores de la vida cotidiana de los colombianos.

A partir de la revisión de 9000 artículos de prensa publicados entre 1990 y 2004 , en su investigación sobre las representaciones sociales de la paz, Hurtado y Lobato (2009) destacan que en Colombia se creía que todos los males del país tenían su origen en las acciones de los grupos guerrilleros, salvo el tiempo ( 1989 y 1993) en que Pablo Escobar tuvo un papel protagónico. En esta dirección, los investigadores sostienen que "se pretendió hacer creer que, si en Colombia no existiesen tales grupos, el país no padecería los problemas de subdesarrollo que presenta" (Hurtado y Lobato, 2009: 98). Los grupos guerrilleros se describieron como una

\footnotetext{
1 La encuesta de percepción ciudadana en Ibagué se aplicó a 1001 personas por Ipsos Napoleón Franco. La muestra fue ponderada por nivel socioeconómico, género, zona de la ciudad, rangos de edad y ocupación, con base en información del Censo DANE 2005 con proyecciones de población 2016. Margen de error: para el total de la muestra, 3.1\% con 95\% de confianza para fenómenos de ocurrencia de 50\%. Se aplicó del 27 de octubre al 28 de noviembre de 2016. Véase Ibagué Cómo Vamos (2016).
} 
insurgencia sin fundamento ideológico, financiada por actividades ilícitas, y capaz de sumir al país en un sistema totalitario si llegaba al poder.

Las situaciones protagonizadas por las guerrillas y acumuladas durante tantos años generaron la percepción de que éstas encarnaban la suma de todos los males del país y se caracterizó a sus dirigentes como seres sedientos de sangre y que no los conmovía ningún sufrimiento. De ahí que esa prédica de emprender una ofensiva total contra las organizaciones guerrilleras fue de buen recibo por la población colombiana y se le extendió a este Mesías (Uribe) la potestad para actuar sin cortapisas legales y anteponer los fines a los medios (Hurtado y Lobato, 2009: 98)

Ahora, el 2 de octubre de 2016 el gobierno convocó a un plebiscito para que los ciudadanos refrendaran o rechazaran el acuerdo de paz firmado entre el gobierno y las FARC. Actores políticos y sociales se alinearon en dos bandos: unos apoyaron el sí y otros preferían el no. Debe decirse que en el epígrafe se sugiere una amenaza: los que voten el sí, descansen en paz (como lo hacen los muertos), estable y duradera. ${ }^{2}$ Para algunos observadores extranjeros el rechazo a la paz es, cuando menos, incomprensible. ¿Cómo pueden los colombianos decirle no a un acuerdo que desarmaría a más de 7000 combatientes y que salvaría a miles de personas?

Del modo en que lo recuerda Lynn Davies (2004), en situaciones de posconflicto, la "nueva normalidad" puede abrir espacios para que los ciudadanos enfrenten la injusticia social, la corrupción o la agresión, de ahí que el fortalecimiento de la sociedad civil se constituya en un elemento clave cuando las relaciones comunitarias de confianza se han deteriorado o destruido. Pero, como se ha planteado, las lógicas de la guerra no desparecen, las maneras como se construyen las identidades regionales, la imagen de sí mismos y del país, de su futuro y de su pasado, no necesariamente se transforman. Así que el análisis de las representaciones del otro aporta elementos para la elaboración de acciones públicas, comunitarias y privadas que contribuyan a reconstruir el tejido social y a evitar la reproducción de la violencia.

El presente artículo aborda esa representación del otro en el caso colombiano, como un aporte a la construcción de escenarios que superen la polarización en la que se encuentra el país.

\section{Imaginarios, guerra y posconflicto}

Elsa Blair Trujillo (1995: 49) preguntaba: “icuáles son las implicaciones de una cultura política basada en la exclusión y la 'demonización' del otro? ¿Qué consecuencias pueden producirse en la mentalidad de una sociedad que ha hecho de la fuerza, la violencia y la guerra el espacio privilegiado de relación con el 'otro'?". Estos interrogantes siguen vigentes a pesar de los cambios que ha vivido el país desde entonces: “¿Cuál ha sido la base a partir de la cual se han construido los referentes socioculturales (las formas de representación) de la sociedad? ¿Cuáles son esas formas de representación de los diferentes actores que no encuentran otro camino que la violencia? ¿De qué se nutren las 'representaciones sociales' en el país?" (Blair, 1995: 49).

Ahora bien, las representaciones sociales remiten a los referentes comunes a partir de los cuales los sujetos construyen realidades comunicables y, en este sentido, colectivas. Se trata, claro, de las definiciones típicas de objetos y eventos, por ejemplo, de lo que significa ser joven, adulto, hombre o mujer. Giménez (2007) diferencia la cultura pública, de las representaciones sociales. A la primera la entiende como las matrices desde las cuales se despliegan significaciones recurrentes. A las segundas las define como los esquemas cognitivos que permiten a los sujetos orientarse en sus universos sociales. Sin embargo, estas dos dimensiones se encuentran fuertemente vinculadas: "En efecto, por una parte las experiencias comunes que conducen a la formación de esquemas y representaciones similares en los individuos son mediadas por la 'cultura pública'; y por otra parte la 'cultura pública' resulta de la objetivación de esquemas y significados en un pasado más o menos reciente" (Giménez, 2007: 20). Así que las representaciones sociales no pueden pensarse por fuera de las relaciones socioculturales en las que se desarrollan, de ahí que se entienda que "la cultura es la organización social del sentido, interiorizado de modo relativamente estable por los sujetos en forma de esquemas o de representaciones compartidas, y objetivado en formas simbólicas, todo ello en contextos históricamente específicos y socialmente estructurados" (Giménez, 2007: 20).

Las representaciones sociales se relacionan entonces con la construcción social de la realidad, se trata

\footnotetext{
2 Se alude de manera irónica al título del acuerdo: Acuerdo final para la terminación del conflicto y la construcción de una paz estable y duradera. Se puede consultar en: http: / www.altocomisionadoparalapaz.gov.co/procesos-y-conversaciones / Documentos\%20compartidos /24-11-2016NuevoAcuerdoFinal.pdf
} 
del modo como cada grupo social define su mundo, establece su historia y proyecta sus acciones. En efecto, Duveen plantea que:

Una representación social tradicionalmente es comprendida como un sistema de valores, ideas y prácticas con una doble función: primero, establecer un orden que permita a los individuos orientarse a ellos mismos y manejar su mundo material y social; y segundo, permitir que tenga lugar la comunicación entre los miembros de una comunidad, proveyéndoles un código para nombrar y clasificar los diversos aspectos de su mundo y de su historia individual y grupal [cit. en Rodríguez Salazar, 2003: 56].

Se trata de convenciones que a un tiempo facilitan la coordinación de los individuos pertenecientes a un espacio social y establecen parámetros para que éstos se piensen a sí mismos, cataloguen a los demás y reaccionen a las contingencias. Así, Rodríguez Salazar (2003: 57, citando a Moscovici), propone que las representaciones permiten, en primer lugar, "Hacer convencionales los objetos, personas y eventos que encontramos. Les otorgan una forma definitiva, las localizan en una categoría y gradualmente las establecen como modelo de cierto tipo, distinto y compartido por un grupo de personas". En segundo lugar, las representaciones sociales hacen prescripciones, en el sentido de que "se nos imponen con una fuerza irresistible. Esta fuerza es una combinación de una estructura que se nos presenta antes de que empecemos a pensar y sobre una tradición que nos marca qué debemos pensar" (Rodríguez Salazar, 2003: 57).

En este sentido, las representaciones son sociales por su carácter compartido, su génesis y sus funciones. Lo social interviene de diversas maneras: por el contexto concreto en el cual están situadas personas y grupos, por la comunicación que se establece entre ellos, por los cuadros de aprehensión que les proporciona su bagaje cultural, así como por los códigos, valores e ideologías ligados a las posiciones o pertenencias sociales específicas. Los imaginarios sociales cumplen un papel similar. Cárdenas Ruiz (2013: 45, citando a Taylor) los define del siguiente modo: "Algo más profundo que los esquemas intelectuales que las personas pueden tener cuando piensan acerca de la realidad social de manera desagregada. Yo pienso, antes, en las maneras en que las personas imaginan su existencia social, cómo encajan unos con otros, cómo las cosas se desenvuelven entre ellos, las expectativas que se cumplen normalmente y la normatividad". Para Cárdenas Ruiz, se trata de los esquemas construidos socialmente, que permiten percibir algo como real, de tal forma que pueda ser explicado y posibilite la inter- vención de cada actor. Los imaginarios proporcionan coordenadas de sentido respecto al modo como se percibe a sí mismo y al papel que cada quien ocupa en la sociedad. Por consiguiente, las representaciones sociales del proceso de paz se refieren a este universo socialmente compartido a partir del cual las personas se comunican y orientan su vida cotidiana. Se requiere entonces identificar cuáles son los significados reconocidos de manera convencional y establecer cómo han sido legitimados por dicha colectividad.

\section{Estrategias de recolección y análisis de la información}

Como se dijo en la introducción, se aplicaron varios instrumentos de recolección de la información: entrevistas a profundidad, grupos focales, encuesta de percepción ciudadana, seguimiento a redes sociales, todos ellos instrumentos diseñados con base en los aportes de investigaciones realizadas en Colombia sobre el tema, con el propósito de profundizar en los resultados a partir del análisis de lo ocurrido en el departamento del Tolima.

Vale precisar que este departamento jugó un papel clave en el surgimiento y desarrollo del conflicto armado colombiano. Por una parte, en su territorio se instalaron algunas de las primeras guerrillas de autodefensa liberales y comunistas que lucharon para sobrevivir el aniquilamiento que desplegó el gobierno y el partido conservador, hacia los años de la década de 1950. Al sur del departamento, esas guerrillas se dividieron en "limpios" y en "comunes" y se desató una confrontación entre estas dos agrupaciones. Los primeros fueron armados y entrenados por el ejército y la policía, como apoyo para luchar contra las guerrillas comunistas (que dieron origen a las FARC), mientras que los limpios fueron transformándose hasta convertirse en el Bloque Tolima, una fuerza paramilitar asociada a las Autodefensas Unidas de Colombia. Ambos bandos mantuvieron cierto control territorial $\mathrm{y}$ aglutinaron a familias que desataron una lucha de venganzas (Centro Nacional de Memoria Histórica, 2017). Esta compleja historia del departamento lo convierte en un escenario clave para la lectura de los imaginarios y representaciones sociales sobre la construcción de la paz.

Ahora bien, la encuesta de percepción ciudadana apunta a establecer las convenciones sociales según clase social, edad y género. Aquí son útiles algunas contribuciones teóricas de Almond y Verba (1992) respecto a la cultura política; ellos entienden que ésta es "la particular distribución de las pautas de 
orientación hacia objetos políticos entre los miembros de una nación". Se trata del modo en que los sujetos que forman parte de un colectivo entienden, evalúan y aceptan las instituciones y los procesos políticos. Así, los datos de la encuesta de percepción ciudadana facilitaron obtener una distribución de dichas orientaciones para la población de Ibagué. Por otro lado, se aplicó una encuesta a población víctima del conflicto en el municipio de Chaparral. Los resultados de este ejercicio permiten profundizar en los resultados generales. Los grupos focales y las entrevistas se emplearon para problematizar lo obtenido en la encuesta y ampliar el análisis hacia otros municipios del departamento.

Vale decir que las representaciones sociales o las orientaciones hacia los objetos y procesos políticos no aluden a una esfera armónica ni pacífica, sino que se encuentran diferencias y tensiones. En esta dirección, Martín-Barbero (1991) recoge la noción de hegemonía propuesta por Gramsci para discutir la cultura: los parámetros que orientan la significación social, las convenciones, son producto de una serie de relaciones de poder, de manera que los patrones responden menos a las necesidades de cada grupo social que al modo como los grupos sociales con ventajas han construido su representación de la realidad. Es decir, cada sujeto sólo podría percibir lo que la hegemonía le permita: "Haciendo pensar, que es posible pensar en el proceso de dominación social ya no como imposición desde un exterior y sin sujetos, sino como un proceso en el que una clase hegemoniza en la medida en que representa intereses que también reconocen de alguna manera como suyos las clases subalternas" (Martín-Barbero, 1991: 85). Para Martín-Barbero, no se trata de una situación estática, pues la hegemonía se hace y deshace, se rehace permanentemente en un proceso vivo, en el que se ponen en juego relaciones de fuerza y de sentido, "de apropiación del sentido por el poder, de seducción y de complicidad" (1991: 85). Así, la cultura se constituye en un "campo estratégico en la lucha por ser espacio articulador de los conflictos" (1991: 85). Entonces, este proceso de construcción de la realidad social no es unilateral (de arriba abajo), sino que supone un complejo proceso de reapropiaciones en el que se negocian, intercambian, rechazan, complementan, colaboran, diversas concepciones del mundo, diversas perspectivas. El seguimiento a redes sociales apunta a establecer los puntos de vista de los líderes de las campañas alrededor del plebiscito, como un elemento esencial para identificar la escenificación de la lucha social y política que se expresa en las convenciones sociales sobre la paz en el país.
Las convenciones sociales alrededor del proceso de paz, es decir, las orientaciones cognitivas y valorativas de los tolimenses, se entienden entonces como elementos integrantes de la cultura política local, esto es, como resultado de un complejo proceso de confrontación entre diversos actores por establecer los significados válidos sobre el proceso de paz. La lectura de esa confrontación se desarrollará a partir de la discusión de los elementos aportados por las redes sociales, la encuesta de percepción ciudadana, las entrevistas a profundidad y los grupos focales.
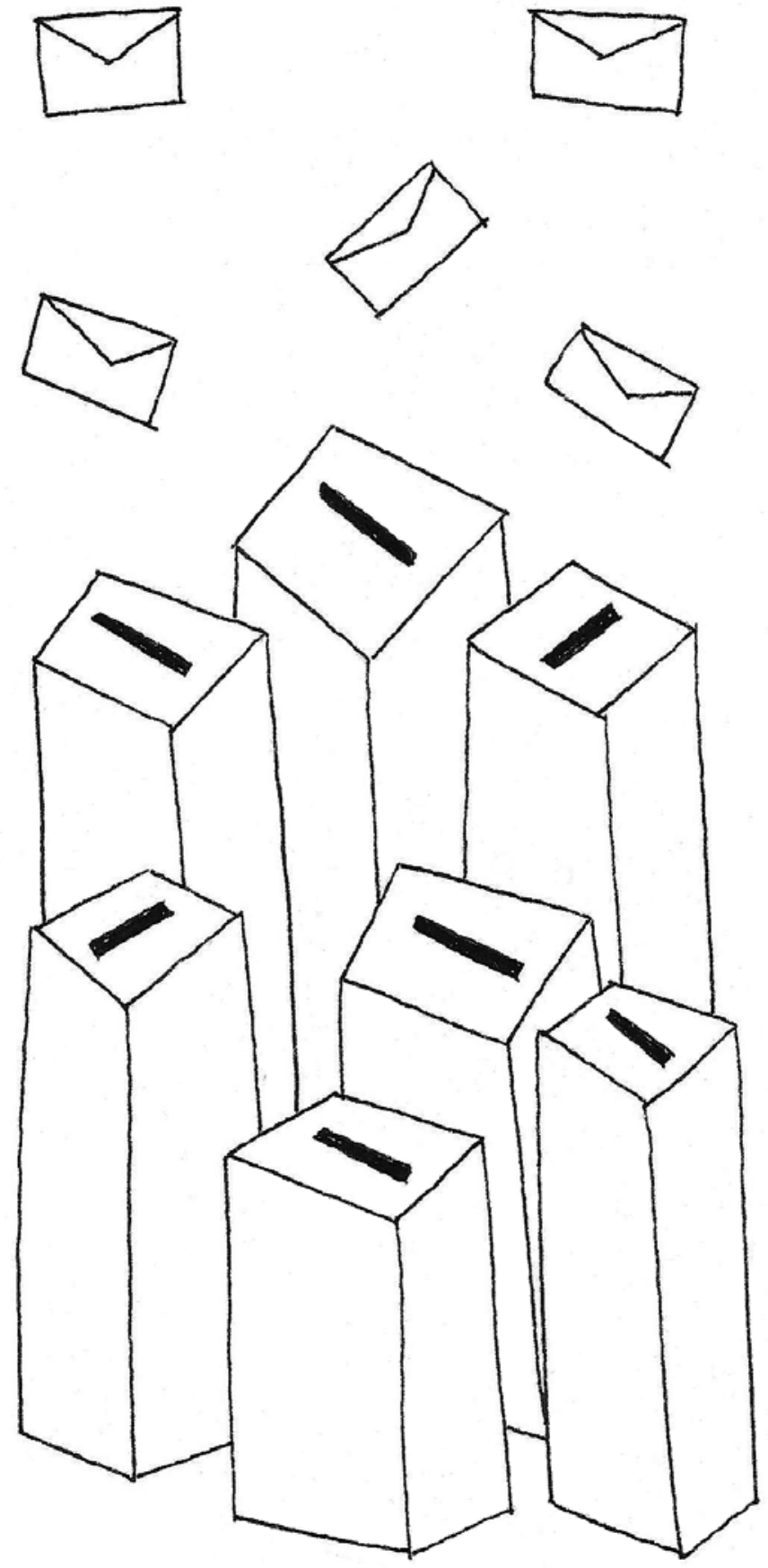


\section{Guerra a la guerra: gestión de odios y miedos}

El 2 de octubre de 2016 los ciudadanos colombianos votaron el plebiscito que el gobierno nacional convocó con el propósito de refrendar el Acuerdo. En efecto, 6431376 personas votaron no al acuerdo de paz, es decir, 50.21\% lo rechazó. Durante los meses de agosto y septiembre se efectuaron campañas a favor y en contra, algunas organizadas alrededor de los partidos políticos, otras por iniciativa de diversos actores con cierta visibilidad pública. Como se intentará demostrar a continuación, algunos de los promotores del no apelaron al miedo y al odio para fundamentar sus campañas, mientras que los promotores del sí respondieron atacando a sus contendientes. Ambos bandos se agredieron desplegando lo que podría denominarse una guerra simbólica. Uno de los escenarios de dicha confrontación fue el de las redes sociales. Para dar cuenta de este proceso se recogieron tuits publicados por impulsores del sí y del no, de políticos, periodistas o actores sociales capaces de generar opinión. Más adelante se presentará el perfil de cada uno de ellos.

\section{Gestión del odio}

El periodista Daniel Samper ${ }^{3}$ ha desarrollado un canal de YouTube a través del cual ha apoyado el proceso de paz. Sus opositores no sólo atacaron sus ideas, sino que amenazaron su integridad: "Gracias a nuestra seguridad democrática aquí están felices los humoristas, así algunos sean parásitos. Siga así” (tuit publicado por el expresidente Álvaro Uribe Vélez, líder de las campañas por el no). ${ }^{4}$ Otros cuestionamientos y ataques apelan a su posición social: "No es lo mismo vivir y hablar de la guerra desde el Chocó que desde el Chicó" (tuit de Andrés Clavijo, en respuesta a Daniel Samper). En efecto, la familia de Samper pertenece a la clase política nacional, tan tradicional como el barrio El Chicó, de Bogotá, y vale la pena recordar que su tío, el expresidente Ernesto Samper, se mantuvo en el poder en medio del escándalo político más importante de finales del siglo $\mathrm{xx}$, incluso cuando se comprobó que la mafia financió su campaña. Estos vínculos familiares sirvieron como parte del arsenal que sus rivales emplearon contra Daniel Samper: “¿Eres medio cínico, verdad amigo? Qué tal, su tío fue presidente gracias al cartel de Cali” (tuit de Daniel Quintero).

Los ataques personales (insultos, señalamientos y provocaciones), fueron usados reiteradamente contra los promotores del sí. Por ejemplo, el senador Iván Cepeda fue tildado de asesino y "tarado": "La mejor forma de acabar la guerra es sacando asesinos como Iván Cepeda, Piedad Córdoba, JM Santos, etc. del ámbito político" (publicado por Colombia NO). O, por ejemplo: "no sea tarado no es contra la tal paz es contra los acuerdos infames dictados por las FARC" (tuit de Guasón Veneno). Otros lo señalaron de "marxista" o de "comunista", empleando estos términos como un insulto: "Esta polémica está tan trasnochada como su marxismo-leninismo. Manipulador compulsivo" (Aneurin, 1950). En efecto, según estos tuiteros, quienes votaron por el sí terminarían "entregando" el país a las FARC: "Vote SI para qué apoye el congreso fariano, Teodora Bolívar, Iván Cepeda Márquez y los 5 honorables senadores de las far Apoye el Socialismo" (por CH - MAX). A su vez, los promotores del sí también fueron acusados de desarrollar tratos con las FARC para obtener dividendos: "ahora podrás sacar el dinero que te regalaron los narcoterroristas de las FARC" (publicado por Giorgio Rafael Suarez). Otro caso similar sería el siguiente: "Mi Voto es No los colombianos q votan por el Si lo hacen por mermelada o como Funcionarios Públicos por miedo como B/quilla" (por Sergio S.)

Desde esta perspectiva, los acuerdos de paz terminarían beneficiando a las FARC, pues los combatientes desmovilizados contarían con prebendas y beneficios del Estado: "Estoy haciendo lista de mis pecados para ver si hago méritos ante Gobierno y maldita sea, no me alcanzan ni para un empleo" (publicado por Silvio Ramírez). Es decir, la paz premiaría a los malhechores: "Hablan de paz y acomodan las FARC. NO al plebisantos” (por Rubén Darío Yepes), de modo que éstos obtendrían el perdón sin dar nada a cambio: "para poder decir SI que perdón se acompañe de \$ para pagar daños ya que confesión los deja desvergonzados" (por Silvio Ramírez).

Evidentemente, este tipo de argumentaciones coloca la discusión en función de la lógica "amigo-enemigo". En efecto, así se

dificulta la posibilidad de dialogar, de llegar a acuerdos a partir del debate de ideas y propuestas de solución de

3 Daniel Samper Ospina es un periodista, escritor y youtuber colombiano. Es columnista de la revista Semana y director de Productora Semana, una empresa de Publicaciones Semana. A mediados de 2016 se convirtió en youtuber. Actualmente tiene 1854032 seguidores en su cuenta de Twitter; 293933 suscriptores en su canal de YouTube y 13990005 de visualizaciones en el mismo.

4 Se mantiene la ortografía y la puntuación de los tuits, según fueron publicados. Por esta razón se presentan palabras incompletas, así como algunos "errores" de sintaxis. 
asuntos que son de interés común. Las personas, los hechos y las cosas ya no se miden por lo que son en sí, sino en función de lo que representan a favor o en contra de la confrontación: nosotros-ellos [Lozada, 2004: 196].

\section{Gestión del miedo}

La senadora Paloma Valencia Laserna ${ }^{5}$ promovió el no. Considera que el plebiscito es una farsa: "El plebiscito es un gran engaño. No pretende consultar la voluntad de los colombianos, sino fingirla", esto significa que la senadora está en desacuerdo con la participación política de los exguerrilleros de las FARC: "\#PazesvotarNO Porq los crímenes merecen castigos Porq no debe haber asesinos secuestradores y narcotraficantes en la política". Además de atacar a sus rivales, ella plantea una serie de advertencias, entre ellas: "reducción del Ejército es un grave error, aún con los acuerdos firmados se necesitará muchos soldados para controlar los nuevos criminales", o: "Vienen 7 actos legislativos para cambiar nuestra constitución al gusto de las FARC y 30 proyectos de ley bajo el \#ActoLegislativoParaLaPaz". Otro ejemplo más: "Defenderemos la justicia como fundadora de la paz y lucharemos contra la impunidad y el premio a los violentos".

Su desconfianza frente al proceso es evidente y cuestiona a Juan Manuel Santos: "De sus primeras verdades: el presidente reconoce q hace lo q le da la gana Ni Corte ni ley". Cuestiona lo que para ella son las prácticas de quienes promueven el sí al sugerir que están "comprando" a la población: "Gobierno confunde recursos públicos con obligación de respaldar al gobierno. Casas por plebiscito Ayuda de Coldeportes por deportistas sumisos". Los ataques también se extienden hacia los ministros: "Ministros: pareciera q después de 6 años de tener abandonada a Col han decidido q en posconflicto si van a gobernar". En concordancia con lo anterior, los llama mentirosos: “\#CristoMiente todos los pecados de Santos pretenden lavarlos diciendo q Uribe hizo lo mismo. Jamás tuvo q comprar votos la gente lo quería".

La campaña por el no se alimenta tanto del odio como del miedo: miedo a que las FARC tomen al país y lo conviertan en "otra Venezuela", con los problemas del socialismo del siglo xxi. La búsqueda de la paz, en su argumentación, no puede reconocer a las FARC como actor político. En sus palabras, no es la paz del país, sino la paz de Santos: "Si gana el NO, podremos construir una paz a nuestra medida. A la medida del futuro de nuestros hijos".

En el mismo sentido van los comentarios del senador José Obdulio Gaviria: "El espíritu del acuerdo es una alianza política entre Santos y Timochenko". Cree que el acuerdo fue firmado con el objetivo de perseguir a la "oposición" que él representa, es decir, de articular un movimiento en contra de la ideología del Partido Centro Democrático. Según esto, el acuerdo no brinda ninguna garantía para la ciudadanía, debido a que existen muchos vicios de fondo: "Ante el plebiscito propuesto por Santos, el lema de campaña por el NO debería ser: SI A LA PAZ, NO A LA ENTREGA". Para él, no existe un buen acuerdo en lo concerniente a dejar las armas y el sometimiento de las FARC a la justicia. "Las FARC y el Gobierno acordaron un tipo de justicia que no va a perseguir a los crímenes de la guerrilla". Otra muestra de este tipo de postura se puede ver en el siguiente tuit: "Pretenden ser protagonistas de la política y no responder por sus crímenes", y rechaza lo que juzga como impunidad: "En otras palabras: la amnistía es cero responsabilidades penales, civil y anula antecedentes penales. Impunidad total. Eso quieren, eso tendrán".

También piensa que votando no se evitará entregar el país a las FARC. Entonces apela al recuento de los daños causados por la guerra: "Las FARC son una organización antidemocrática, lo que resulta un peligro. Porque tendrán un Centro de Pensamiento". A esto se suma un continuo ataque al gobierno por la forma en que negoció el acuerdo ("El SÍ es una alianza política entre el Estado y la guerrilla de las FARC"), así como por el trato a los opositores: "Gobierno no quiso venir a debate sobre 'paz' al senado. Alegó 'compromisos adquiridos con posterioridad' ¿Saben con quién? Con las FARC".

En este rápido panorama puede observarse que la campaña por el no promovió los odios y temores que las FARC, el proceso y el mismo gobierno despertaron. En las palabras de José Obdulio y de Paloma Valencia, el proceso se desarrolló entre aliados, no entre enemigos que han sostenido una cruenta guerra por más de cinco décadas. Desde su perspectiva, esta alianza pone en peligro al país, pues tarde o temprano terminará en manos del comunismo. Sus detractores, los promotores del sí, son presentados como "traidores" que tienen un pasado ominoso, así

5 Paloma Susana Valencia Laserna es una analista política y abogada. Fue elegida senadora de la República de Colombia por el Partido Centro Democrático para el periodo 2014-2018.

6 José Obdulio Gaviria Vélez es un abogado y político colombiano. Actualmente es senador de la República por el departamento de Antioquia, y miembro del Partido Centro Democrático. Fue asesor presidencial de Álvaro Uribe Vélez durante la mayor parte de su gobierno, y se le considera el estratega detrás de la ideología del expresidente. 
como oscuras intenciones. Las alusiones al contenido del acuerdo son vagas, se reducen a enunciados como "impunidad" y "entrega del país". Con algunas excepciones, los promotores del no evadieron el debate sobre los acuerdos, atrincherados en su estrategia de movilización de emociones.

\section{Guerra a la guerra}

Pero los ataques fueron respondidos. Por ejemplo, Daniel Samper dirige sus dardos contra el expresidente Uribe, caricaturizándolo: "El amigo Uribe se opondrá con pies y manos al proceso de paz porque el amigo Uribe sabe que sin FARC tampoco hay Uribe". Otro caso de este tipo de tuit es el siguiente: "Uribe dice que las FARC terminarán de paramilitares: ¿se podría pensar que, por esa vía, terminará simpatizando con ellas?". Así que, en contra de la idea de la oscura alianza entre las FARC y el gobierno, Samper contraataca planteando una tenebrosa asociación entre el expresidente Uribe y el paramilitarismo. En esta línea, Samper recuerda con ironía que muchos personajes del mundo respaldan el proceso: "La Corte Penal Internacional, Obama, Papa Francisco, todos cooptados por castrochavismo, mi doctor Uribe: ahora sí nos llevó el que nos trajo”. Con un tono similar, el expresidente Andrés Pastrana ${ }^{7}$ se convierte en objeto de sus críticas: "No se preocupen que, si gana el NO, Pastrana renegocia el proceso de paz", o: "Pastrana regaló a las FARC un reloj y 5 municipios; ahora protesta contra un proceso que a diferencia del suyo sí es serio".

Daniel Samper se esfuerza por "desmarcarse" de la descripción que sus opositores han hecho de su persona y su acción. Es decir, se esmera en tomar distancia de las FARC: "Porque detesto a las FARC, celebro el proceso: desmovilizarlas es la victoria del estado sobre ellas... Las remataremos en las urnas". El apoyo al proceso de paz no significa respaldar a las FARC como actor político: "Como detesto a las FARC, pero jamás empuñaré un arma, estoy feliz de poderlas derrotar en las urnas. Por eso voy a votar por el SÍ". Pronunciarse por el proceso de paz se convierte en una posición contra la muerte, contra la guerra: "Me resisto a que el des- tino de los jóvenes más humildes de Colombia, sean del ejército o de las FARC, sea matarse unos a otros: yo voto Sí".

Desde su perspectiva, quienes promueven el no están del lado de la guerra y la muerte y por tanto deberían asumir los costos de su postura: "Si quiere más guerra, vaya a la trinchera y pelee usted mismo»: voto por el NO debería incluir esa cláusula”. En este sentido, tales promotores evaden los debates, dedicándose a sembrar la discordia: "Que no se empiecen a chupar ahora los del NO, eso es cobardía... expongan sus puntos y debatan..."

El senador Iván Cepeda Castro ${ }^{8}$ desarrolla una estrategia similar: contraataques, cuestionamiento a los rivales ("Cualquier forma de la envidia es mezquina. Pero sentir envidia porque se ha logrado la paz es ruin"), críticas ("En vez de resentimientos y envidia algunos expresidentes deberían sentir orgullo patriótico porque se está logrando la paz en Colombia”) y desafíos ("Hago este vaticinio: los primeros que pedirán cierre de Jurisdicción Especial para la Paz serán quienes hoy claman por "paz sin impunidad"). El senador también plantea los beneficios del fin de la guerra: "Votar Sí es decirle Sí a Colombia"; "Hacer la Paz cuesta lo que valen 7 días de la guerra", "Viene un periodo de alegrías y cosas buenas para Colombia".

Pero el enfrentamiento simbólico entre estas figuras políticas no se queda aquí. Algunos promotores del sí atacan a sus rivales a nivel personal: "creo que tú sigues a un dirigente político que creó las Auc y también habla de moral!" (tuit de Daniel Bustos dirigido a Paloma Valencia). Su moral, sus creencias o su posición social son parte de los argumentos: "Ninguno, ninguno, ninguno de estos politiqueros sabe de eso de "autoridad moral”. ¡Cierren la boca y controlen la pluma!!!” (tuit de Fernando Londoño Sua dirigido a Paloma Valencia). Otro ejemplo: "Sólo un desquiciado puede tuitear semejantes barbaridades al saber qué falta para el acuerdo final. Demasiada mala fe la suya” (tuit de Gabriel Ángel dirigido a José Obdulio Gaviria). Como se puede leer, se responde al fuego con fuego: "el odio q usted y su jefe crea entre los colombianos d bien, nos hacen pensar q la patria no merece haberlos parido" (tuit de Álvaro Ernesto Rojas dirigido a José Obdulio Gaviria).

\footnotetext{
7 Andrés Pastrana fue presidente de Colombia entre 1998 y 2002. Adelantó negociaciones con las FARC en la llamada zona de distensión, una zona de $42000 \mathrm{~km}^{2}$ controlada por esta guerrilla y que se convirtió en lugar para resguardar secuestrados y fortalecer tanto la economía como la capacidad militar de la guerrilla.

8 Iván Cepeda Castro es un político y defensor de derechos humanos colombiano, filósofo de profesión. Se desempeñó como representante en la Cámara entre 2010 y 2014, actualmente es senador por el Polo Democrático Alternativo. Es el vocero oficial del Movimiento de Víctimas de Crímenes de Estado (Movice), organización nacida en 2003 con el fin de agrupar a los familiares de víctimas de crímenes de lesa humanidad y las organizaciones que trabajan por los derechos humanos. Su labor en el campo de los derechos humanos lo hizo merecedor del Premio Medalla de la Libertad Roger Baldwin en 2007.
} 
En pocas palabras, las campañas desarrolladas alrededor del plebiscito incluyeron ataques y contraataques en los que se apeló a la descalificación personal, la mentira, las verdades a medias y la generación de temores. Cabe preguntar si esta agresividad simbólica no supone la continuación del conflicto por otros medios. Asimismo, queda la inquietud por los efectos que este tipo de confrontación ha generado en el actual proceso de construcción de paz.

\section{Rechazo de la participación política de las FARC}

El 29 de junio de 2016, la revista Semana publicó un artículo que reseña una encuesta realizada en los meses de marzo y abril por el Barómetro de las Américas en zonas de consolidación territorial, es decir, en áreas donde el conflicto se desarrolló con especial intensidad; los resultados reflejan que las personas están dispuestas a cohabitar, pero no a relacionarse con los excombatientes.

Este hallazgo es coherente con dos sondeos previos, por ejemplo: “¿Qué piensan los colombianos después de siete años de justicia y paz?" (Centro de Memoria Histórica, 2012) y ¿Qué piensan los colombianos del proceso de paz? (Observatorio de la Democracia, 2013). Ambos instrumentos indagaron la posibilidad de reconciliación y convivencia con exintegrantes de los actores ilegales del conflicto armado: "si bien existe una aceptación media de la población para interrelacionarse en espacios sociales comunes con los desmovilizados, también se encuentra resistencia para la consolidación de relaciones sociales humanas estrechas, tales como la generación de vínculos emocionales entre sus hijos(as) con dichas personas" (Centro de Memoria Histórica, 2012: 99).
En una encuesta realizada por Cárdenas (2013) se abordan las actitudes e imaginarios de los bogotanos frente al proceso de paz. Para los propósitos del presente análisis se destaca la respuesta a la pregunta: "Ante un eventual pacto entre el gobierno y la guerrilla estaría usted de acuerdo con..." (véase gráfica 1).

De la gráfica 1 sobresale que $75 \%$ de los bogotanos encuestados está de acuerdo con que los guerrilleros se incorporen a la vida civil, mientras que sólo $27 \%$ lo está respecto a su participación en política. Como se verá más adelante, la mayoría de los ibaguereños encuestados por Ibagué Cómo Vamos rechazan la participación política de los desmovilizados de las FARC, mientras que poco más de $40 \%$ de ellos está dispuesto a tener a un guerrillero desmovilizado como vecino.

Ambas encuestas presentan resultados similares, pese a aplicarse en momentos y ciudades diferentes: una en Bogotá en 2013, y otra en Ibagué a finales de 2016.

En un estudio financiado por la United States Agency for International Development (USAID), denominado Cultura política de la democracia en Colombia, 2013: Actitudes democráticas en el contexto del proceso de paz (García, Rodríguez y Seligson, 2014), se aplicó una encuesta nacional que pretendía medir las actitudes de los colombianos hacia la eventual participación política de las FARC.

Lo primero que indagamos en relación con el tema de participación política, fue la favorabilidad de la población respecto a que el gobierno colombiano genere las garantías para que los desmovilizados de las FARC participen en política [...] entre el 65\% (muestra zonas de conflicto) y el $71 \%$ (muestra nacional) de los encuestados no está de acuerdo con que el gobierno garantice la participación política de los miembros de esta organización [García, Rodríguez y Seligson, 2014: 99].

\section{Gráfica 1 Actitudes e imaginarios frente al proceso de paz - Bogotá}

Ante un eventual pacto entre el gobierno y la guerrilla estaría usted de acuerdo con:

Reincorporación de los guerrilleros a la vida

Participación política de las FARC

Penas alternativas

Perdonar a guerrilleros

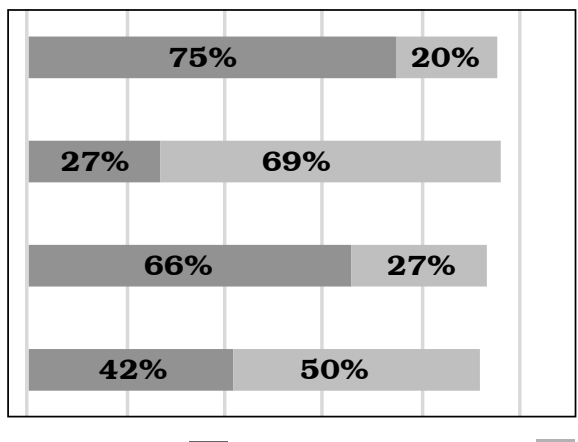

De acuerdo

Fuente: Cárdenas (2013). 
Asimismo plantean:

En la misma línea de los resultados anteriores, los encuestados, tanto de la muestra nacional como de la muestra de zonas de conflicto, no aprueban la eventualidad de que desmovilizados de las FARC participen en elecciones local, de congreso o presidenciales, apenas el $15 \%$ acepta la participación de los desmovilizados de las FARC en elecciones locales. Por su parte cerca del $12 \%$ aprueba la participación de esta organización en elecciones presidenciales o del congreso [García, Rodríguez y Seligson, 2014: 101].

\section{El caso de Ibagué: percepción ciudadana}

A continuación se analizan algunas respuestas a lo inquirido en la Encuesta de Percepción Ciudadana aplicada en Ibagué a finales de 2016. Se preguntó qué tan de acuerdo estaba con las siguientes afirmaciones: ${ }^{9}$

Puedo tener como vecino a una persona desmovilizada de la guerrilla

Usted tiene responsabilidad en el proceso de reconciliación Las personas desmovilizadas de la guerrilla pueden participar en política

Las personas desmovilizadas de la guerrilla son víctimas del conflicto armado
Los enunciados indagan específicamente dos temas: 1) la actitud frente a situaciones sociales cotidianas que el acuerdo de paz generaría, como la convivencia con desmovilizados y su participación en política y 2) el nivel de responsabilidad que el encuestado asume en el proceso de reconciliación. Para cada pregunta se obtuvo información por clase social (por estratos), ${ }^{10}$ edad y género.

La pregunta: ¿puedo tener como vecino a una persona desmovilizada de la guerrilla? pretende medir la capacidad del ciudadano ibaguereño para participar en esta atmósfera de reintegración en un escenario de construcción de paz.

Los resultados que se registran en la gráfica 2 exhiben que el mayor porcentaje de quienes se encuentran totalmente de acuerdo con la idea de tener a un desmovilizado como vecino (26.14\%) son los encuestados de estrato alto. Pero también el estrato alto tiene el mayor nivel de desacuerdo (30.15\%) frente a la posibilidad de tener a un desmovilizado de las FARC como vecino. A su vez, el estrato medio cuenta con la mayor cantidad de personas $(48.51 \%)$ con algún nivel de acuerdo frente a la posibilidad de tener a un desmovilizado como vecino y menor nivel de desacuerdo (26.36\%).

Al observar las contestaciones se encuentra que el grupo de personas de más de 55 es el que está en mayor desacuerdo (32.48\%). El panorama cambia para

\section{Gráfica 2 \\ ¿Puedo tener como vecino a una persona desmovilizada de la guerrilla? Grupo - Estratos (en \%)}

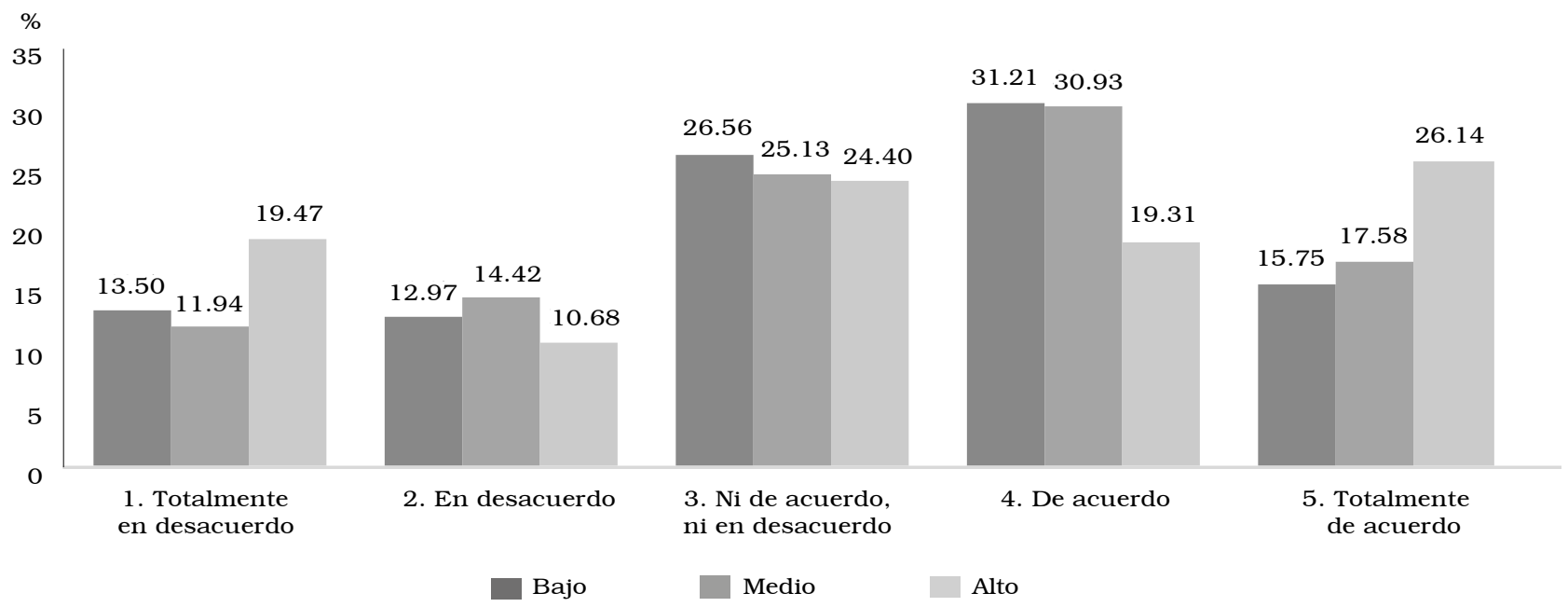

Fuente: Elaboración de los autores.

9 Las personas encuestadas seleccionaron una de las siguientes alternativas: totalmente de acuerdo; de acuerdo; ni de acuerdo ni en desacuerdo; en desacuerdo; totalmente en desacuerdo.

${ }^{10}$ La clase baja implica los estratos 1 y 2 . La clase media incluye los estratos 3 y 4 . La clase alta se refiere a los estratos 5 y 6 . 
los encuestados de 18 a 25 años, pues éstos presentan el menor porcentaje de personas con algún nivel de desacuerdo frente a la posibilidad de contar con un vecino desmovilizado de las FARC (21.77\%). Sin embargo, sólo $48.67 \%$ de las personas de esta edad respondió que estaba totalmente de acuerdo o de acuerdo con la pregunta. Esto permite plantear como hipótesis que los jóvenes están más abiertos a un posible escenario de reconciliación.

De las personas entre los 36 y los 45 años, 50.82\% manifestó algún nivel de acuerdo con la posibilidad de contar con un vecino desmovilizado de las FARC, de modo que este grupo es el que está más dispuesto.

Además, $51.95 \%$ de los hombres tiene algún nivel de acuerdo con tener a una persona desmovilizada como vecino, mientras que sólo $43.41 \%$ de las mujeres opina de esa forma.

En síntesis: los encuestados hombres, las personas pertenecientes a la clase media, así como aquellos entre 18 y 25 años y quienes tienen entre 36 y 45 años, se encuentran más dispuestos a tener un desmovilizado de las FARC como vecino.

En contraste con los resultados obtenidos hasta ahora, la mayoría de quienes contestaron rechaza la idea de que las FARC participen en política. Casi $60 \%$ de los encuestados de las clases baja y alta $(58.85 \%$ y $58.77 \%$ respectivamente) está en desacuerdo o totalmente en desacuerdo con esta idea. En cambio, $48.87 \%$ de encuestados de clase media está en desacuerdo, mientras que $34.83 \%$ de dicha clase acepta la participación política de las FARC (véase gráfica 3).

Por su parte $65.04 \%$ de las personas entre los 26 y los 35 años se opone a la participación política de las FARC, mientras que sólo $18.43 \%$ la acepta. Un panorama similar se observa para los grupos de 18 a 25 años (50.07\% rechaza la idea y $27.89 \%$ la aprueba) y de 36 a 45 años (se obtuvo $59.86 \%$ de rechazo y 23\% de aceptación). Las personas de más de 55 años son más optimistas, es decir, $36.94 \%$ de ellas acoge la idea mientras que $46.97 \%$ manifiesta su oposición.

Más hombres (33\%) están de acuerdo con la idea de la participación política de las FARC que las mujeres (21.77\%). Sin embargo, más de la mitad de ellos y ellas rechazan esta afirmación $(50.76 \%$ de los varones y $58.78 \%$ de las mujeres).

En términos generales, los hombres, las personas mayores de 55 años y las que pertenecen a la clase media son quienes en mayor medida se encuentran de acuerdo con la idea de la participación política de los desmovilizados. No obstante, como se anotó, la mayoría rechaza la participación política de las FARC. La discusión que sigue pretende profundizar el análisis de este fenómeno a partir de los resultados de los grupos focales y entrevistas.

Percepción de las víctimas sobre la participación política de las FARC

Desde otro ángulo, en 2017 se hicieron las mismas preguntas a población víctima del conflictito armado residente en los municipios de Chaparral, Lérida e Ibagué en el departamento del Tolima.

La población participante estuvo conformada por mujeres y hombres desplazados por el conflicto interno del país y registrados en el Registro Único de Víctimas

\section{Gráfica 3 \\ Actitud frente a la participación en política de las farc Las personas desmovilizadas de la guerrilla pueden participar en política Grupo - Estratos (en \%)}

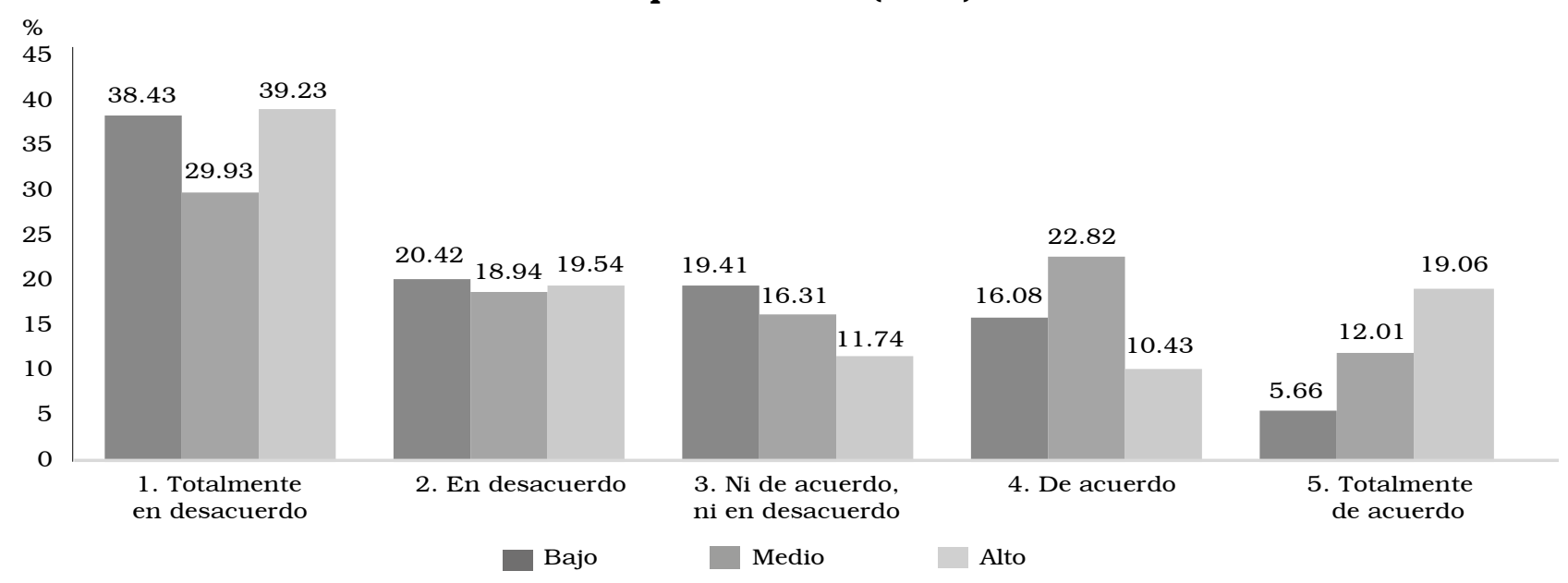

Fuente: Elaboración de los autores. 
(RUV) residentes en los municipios recién mencionados. En total participaron 238 víctimas ( 156 mujeres y 82 hombres), cuyas edades oscilaban entre los 18 y los 80 años. La mayoría posee estudios de primaria ( 130 personas, algunos de los cuales no superan el tercer grado; $80 \%$ son individuos desplazados provenientes del departamento del Tolima, en especial de las zonas rurales del municipio de Chaparral y Planadas.

A la pregunta ¿puedo tener como vecino a una persona desmovilizada de la guerrilla?, 76.5\% manifestó estar en desacuerdo o completamente en desacuerdo. En Chaparral, 70\% expresó estar completamente en desacuerdo. En contraste, en Lérida, 44.4\% evidencia no tener inconveniente en ser vecino de un desmovilizado de la guerrilla.

Por su parte, al inquirir por la participación política de la guerrilla, 80.7\% de las víctimas rechazó esta idea.

Además, al indagar con los encuestados si los desmovilizados de la guerrilla son víctimas del conflicto armado, $70.6 \%$ no está de acuerdo o está completamente en desacuerdo, pues los identifican como victimarios. Esta idea es compartida por la mayoría de las personas encuestadas en los tres municipios.

Finalmente, al preguntarles si consideran que tienen responsabilidad en el proceso de reconciliación que se viene llevando a cabo, se reveló que $54.5 \%$ piensa que no tiene responsabilidad, frente a $45.5 \%$ que asume una responsabilidad en este proceso.

Estos resultados dan cuenta de la percepción de las víctimas del conflicto armado frente a la participación en la vida social y política de las FARC. En los grupos focales con víctimas se evidenció un malestar por la información que circulaba en redes sociales alrededor de las campañas desarrolladas con ocasión del plebiscito. Como se ha anotado, en ellas se hizo referencia a que las personas desmovilizadas de la guerrilla tendrían una serie de prebendas tales como un salario mínimo de por vida, estudio y vivienda; este aspecto quedó de manifiesto en el siguiente comentario:

uno no cuenta con el gobierno... ¿cuánto le van a dar a cada guerrillero por entregar el fusil? y ¿si ve cómo están? y eso si es puntualito que les está llegando la plata, son como 3 millones de pesos, y si es soldado raso como millón ochocientos; y uno que está en apuros, en crisis, para que le llegue esa ayuda humanitaria... eso es cuando ellos quieran, lo hacen pasar a uno necesidades [comunicación personal, 24 de marzo 2017].
El anterior comentario está relacionado con la experiencia de las víctimas en su proceso de reparación integral al que tienen derecho de acuerdo con la Ley 1448 de 2011 , conocida como Ley de Víctimas y Restitución de Tierras, ${ }^{11}$ la cual establece una compleja institucionalidad que persigue garantizar una reparación integral a partir de la adecuada coordinación intersectorial y territorial. Para que las víctimas sean reconocidas como tales (y por tanto sean beneficiarias de las políticas), deben presentar la declaración de los hechos ocurridos ante las oficinas regionales de la Procuraduría, o de la Defensoría, o de la Personería Municipal o en los Centros Regionales de Atención y Reparación. En los encuentros grupales quedó de relieve el malestar de muchos respecto a la demora en la entrega de las ayudas humanitarias y los procesos de reparación. En efecto, sólo 10\% de la población víctima ha sido reparada de manera integral.

Según las víctimas, las “ayudas” para los desmovilizados es rápida, mientras a ellos les ha tocado esperar para recibir la reparación vía administrativa y, además, no saben si contarán con recursos derivados de los bienes entregados por las FARC. En sus voces, así expresan su molestia:

que haya igualdad, porque uno mira que para ciertos sectores hay una buena forma [...] Nosotros en ningún segundo hemos cogido plata para venir a defendernos y venir a molestar a ninguno. Yo miraba esta semana el tema de todos los bienes que tienen las FARC, se suponía que las FARC iban a entregar los bienes para la reparación de las víctimas; según lo que dice el fiscal es que esos bienes ellos los quieren tomar para el tema polític[o] que se viene en estos momentos [...] yo sé que muchas veces hay que sacrificar algo para tener algo mejor, pero en este caso nosotros como víctimas somos los sacrificados y otros son lo que tienen [...] nosotros en ningún segundo de la vida cogimos un arma para defendernos [comunicación personal, 6 de junio de 2017].

\section{¿La continuación de la guerra por otros medios?}

Es necesario anotar que los excombatientes no recibieron las "ayudas" que criticaron las víctimas. En efecto, han entregado las armas e iniciado un proceso de reintegración. Los recursos que se les dan dependen

11 Congreso de la República, "Ley 1448 de 2011 : Por la cual se dictan medidas de atención, asistencia y reparación integral a las víctimas del conflicto armado interno y se dictan otras disposiciones", en Diario Oficial 48096, del 10 de junio de 2011 , Bogotá. 
de su participación en dicho proceso, es decir, los excombatientes deben participar en actividades de capacitación, de reparación y de gestión de proyectos productivos para obtener hasta $90 \%$ del salario mínimo por cinco años. Por otro lado, no se ha "entregado el país a la guerrilla" ni se ha instalado el comunismo en el país. Entonces, los grupos focales plantean algunas pistas sobre el sentido del rechazo a la participación política de las FARC, así como de los temores y odios que se han construido frente al proceso de paz.

Pienso que la mayoría de colombianos queremos la paz, pero nos da miedo los poderes de la guerrilla [es decir] que ellos tomen poder y que ahí sí se arme un problema peor [...] La mayoría de la población quiere la paz, pero también sabemos que hay intereses económicos detrás de eso. Mucha gente piensa que ellos van [...] por el poder y por el dinero [participante 2 del grupo focal 2: Jóvenes clase media, 18 de mayo de 2017].

Como se observa, los argumentos de los participantes recuperan las ideas planteadas por los promotores del no: en tiempos de paz, las FARC seguirán siendo una amenaza, porque únicamente persiguen el poder y el dinero, en fin, porque "van por lo suyo". Desde esta perspectiva, el proceso de paz se encuentra animado por miedos, rencores y desconfianza. Pero dicha desconfianza no sólo se profesa hacia las FARC, sino que se manifiesta en contra del Estado y los políticos. Así que, frente a la pregunta ¿por qué creen que en el plebiscito ganó el no?, la primera reacción fue: "porque la gente ya no cree lo que dicen los políticos, desconfía” (grupo focal 2: Jóvenes clase media, 18 de mayo de 2017).

Este recelo se articula a la forma como se desarrollaron las campañas, pues no se discutió el sentido y el contenido de los acuerdos, esto es, el análisis de aspectos positivos, negativos o problemáticos; por el contrario, la competencia sirvió para medir las fuerzas políticas del país. De modo que "la discusión era que Álvaro Uribe Vélez estaba en el 'no'. La gente votó motivada por los comentarios que él y sus oponentes hacían, mas no porque realmente nos hayamos enterado de todo lo que hubiésemos tenido que saber" (participante 5, del grupo focal 2: Jóvenes clase media, 18 de mayo de 2017). Los rivales políticos midieron tanto fuerzas como su capacidad para movilizar a la población en torno de sus caudillos:

Se trató de ver quién iba con quién $[\ldots]$ ¿dónde votaron por el "no"? Pues en Antioquia, en la tierra de Álvaro Uribe Vélez. Eso muestra la división del país alrededor de los políticos. No se trata de la paz como tal, la cuestión era quién representaba el "sí" y quién representaba el "no" [participante 5 del grupo focal 2: Jóvenes clase media, 18 de mayo de 2017].

En otras palabras, múltiples fuerzas políticas intentaron encauzar el acuerdo para fortalecer su posición electoral, y para ello emplearon el rencor y el miedo, además del ataque personal a los enemigos. En este contexto el nuevo partido FARC debe justificar sus aspiraciones políticas: "ganó el 'no' porque ha existido la guerra [...] el voto fue una forma que ellos utilizaron para manifestar que no querían que sus victimarios surgieran" (participante 6 del grupo focal 2: Jóvenes clase media, 18 de mayo de 2017). En efecto, no se entiende la actuación de esta guerrilla como un quehacer político, "pues ellos habían matado a sus familias, entonces ¿por qué van a obtener el poder?” (participante 6 del grupo focal 2: Jóvenes clase media, 18 de mayo de 2017). Se trata de una guerrilla dedicada al narcotráfico, indolente, capaz de todo por lograr sus propósitos: "exacto, ahí hay rencor, pero no sólo hay rencor, también hay miedo (participante 2 del grupo focal 2: Jóvenes clase media, 18 de mayo de 2017).

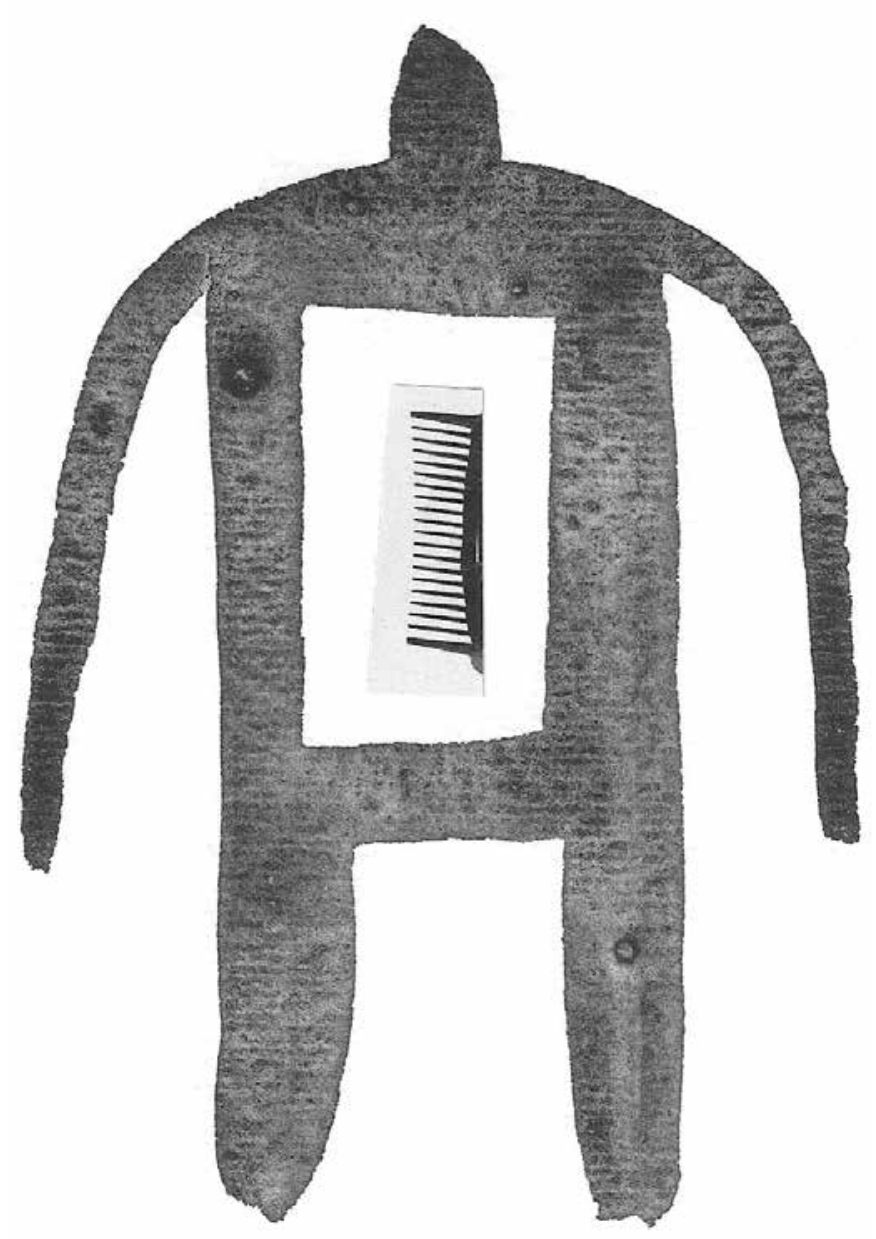


El rechazo a la participación política legal de las FARC se relaciona entonces con la pregunta por la razón de permitirles competir por el poder, por qué se les ha de "premiar". Por esto, vale la pena retomar el trabajo de Fabio López de la Roche cuando señala el denominado "nacionalismo antifariano":

la obra retórica y discursiva adelantada sistemáticamente por Uribe Vélez de 2002 a 2010 [...] fue uno de los componentes centrales de un proceso profundo de redefinición afectiva de la nación, en dirección a su homogenización a través del odio compartido hacia un enemigo definido unilateralmente como "el enemigo número uno de la sociedad": las FARC [2014: 545].

Alrededor de este discurso, el uribismo ha construido los fundamentos de su apuesta política, incluso durante la campaña por el no. El plebiscito expresó la polarización que dicha retórica ha promovido, pues quienes discrepaban del nacionalismo antifariano se convertían en enemigo del país (López de la Roche, 2014; Bonilla, Rincón y Uribe, 2013). Como consecuencia, el plebiscito y el posterior proceso de refrendación de los acuerdos a través del Congreso contribuyeron a que algunos sectores sociales se sintieran manipulados. En otras palabras, este proceso generó el efecto contrario al que los promotores del plebiscito plantearon formalmente: no ayudó a que la ciudadanía se apropiara del proceso de paz.

En mi opinión, el gobierno nacional se equivocó, porque el mecanismo del plebiscito lo que busca es que el gobierno nacional ponga una propuesta y que el pueblo la apruebe. Pero el acto legislativo 01 del 2016 estipulaba que si el Congreso no aprobaba el acuerdo no importaba que toda Colombia hubiese votado por el "sî", ellos tienen la última palabra. Esa votación fue algo simbólico. Lo que se causó con estas votaciones, fue que dividió a los colombianos. Las votaciones quedaron $49 \%$ del "sí" y $51 \%$ del "no". En vez de desarrollar una iniciativa de paz, una iniciativa de unión, lo que pasó con esto fue que nos dividimos [participante 1, estudiante de Derecho, del grupo focal 1: Estudiantes universitarios y docentes, 12 de abril de 2016].

Esta perspectiva coincide con otras señaladas por jóvenes de clase media: "creo que lo que piense el pueblo es diferente a los intereses políticos, es decir, nosotros como pueblo podemos querer algo, pero mientras haya intereses políticos de por medio, todo eso es falso" [participante 5 del grupo focal 2: Jóvenes clase media, 18 de mayo de 2017]. Así que el plebiscito, además de profundizar la división, terminó por confirmar la profunda desconfianza en la política y en el Estado: "y la corrupción, ¿qué? Por ahí empieza el problema de que no haya paz, se roban todo lo que trabajan los otros, eso no es equitativo" [participante 1 del grupo focal 2: Jóvenes clase media, 18 de mayo de 2017].

Como se evidenció con los tuits relativos al plebiscito, la gestión del miedo y de los odios se desarrolló desde casi todos los sectores a través de los ataques personales, esto es, del esfuerzo por desprestigiar al enemigo. Uno de los temas empleados por ambas fuerzas fue el rechazo a las FARC, ya fuera por su indolencia frente a las víctimas, o por el peligro que supondría su proyecto político: para unos, la alternativa era votar no, para otros, derrotarlos en las urnas. Este panorama contribuye a comprender el hecho de que los colombianos estén más dispuestos a convivir con los desmovilizados que a aceptar su participación política. Tanto el resultado del plebiscito como las estrategias de campaña y el rechazo a la participación política expresan el modo en que las lógicas de la guerra -esto es, el esfuerzo por eliminar al enemigo (con la necesaria justificación)- se han socializado; en otras palabras, cómo las lógicas de la guerra se han convertido en un referente cultural que contribuye a que los ciudadanos se definan a sí mismos y definan su participación en la vida colectiva. Como lo recuerdan Davies (2004) y Lambuorne (2004), las condiciones previas al conflicto, y aquellas que se desarrollaron en su interior, prevalecen luego de la terminación de las hostilidades. El reto de la sociedad colombiana es, precisamente, construir la paz a partir de estas representaciones sociales del país que tienen a la guerra como el eje central.

\section{Fuentes}

Almond, Gabriel y SidneyVerba

1992 "La cultura política", en Albert Batllet (ed.), Diez textos básicos de ciencia política, Ariel, Barcelona, pp. 171-201.

Blair TrujILlo, Elsa

1995 "La imagen del enemigo: ¿un nuevo imaginario social?", en Estudios Políticos, núm. 6, pp. 47-71.

Bonilla, Jorge, OMAR Rincón

y Catalina URIBE

2013 "Colombia: Álvaro Uribe Vélez o cuando comunicar es gobernar: comunicación política presidencial en Colombia, 2002-2010", en Matías Ponce y Omar Rincón (coords.), Caudillismo, e-política y teledemocracia, Fin de Siglo, Montevideo.

Cárdenas, Juan Camilo

2013 "Víctimas, victimarios, reinserción y reparación en la práctica", en Blogeconomía <http: / / lasillavacia.com/elblogueo/blog/victimas- 
victimarios-reinsercion-y-reparacion-enla-practica-45436> [ 19 de agosto].

Cárdenas Ruiz, Juan David

2013 "Opinión pública y proceso de paz: actitudes e imaginarios de los bogotanos frente al proceso de paz de La Habana entre el gobierno colombiano y la guerrilla de las FARC", en Ciudad Paz-ando, vol. 6, núm. 1, pp. 41-58.

Centro Nacional de Memoria Histórica

2012 Encuesta Nacional ¿Qué piensan los colombianos después de siete años de justicia y paz? <http:/ / www.centrodememoriahistorica. gov.co/justicia-y-paz / que-piensan-loscolombianos-despues-de-siete-anos-dejusticia-y-paz>.

Centro Nacional de Memoria Histórica

2017 De los grupos precursores al Bloque Tolima

DAVIES, LYNN (AUC). Informe No. 1, CNMH, Bogotá.

2004 "Building a Civic Culture Post-Conflict", en London Review of Education, vol. 2, núm. 3, pp. 229-244.

García, Manuel, Juan Carlos Rodríguez

y Mitchell A. Seligson (eds.)

2014 Cultura política de la democracia en Colombia, 2013: Actitudes democráticas en el contexto del proceso de paz, Universidad de los Andes / United States Agency International Development/Centro Nacional de Consultoría/Observatorio de la Democracia/Vanderbilt University, Bogotá.

Giménez, Gilberto

2007 Estudios sobre la cultura y las identidades sociales, Instituto Tecnológico y de Estudios Superiores de Occidente, Guadalajara.

Hurtado, Guido Germán

Y LUIS EDUARDo LOBATO

2009 Representaciones e imaginarios sobre la violencia colombiana en la prensa nacional (1990-2004), Universidad Autónoma de Occidente, Cali.

IBAgué Cómo VAmos

2016 Encuesta de percepción ciudadana 2016 <https: / / drive.google.com / drive / folders / OB3hOWqfS62mWWXVBRnNRbkdKdEE>.

LAMBOURNE, WENDY

2004 "Post-Conflict Peacebuilding: Meeting Human Needs for Justice and Reconciliation", en Peace, Conflict and Development, núm. 4, pp. 1-24.

López DE LA Roche, FABIO

2014 Las ficciones del poder. Patriotismo, medios de comunicación y reorientación afectiva de los colombianos bajo Uribe Vélez (2002-2010), Universidad Nacional de Colombia, Bogotá.

\section{LozadA, Mireya}

2004 "El otro es el enemigo: imaginarios sociales y polarización", en Revista Venezolana de Economía y Ciencias Sociales, vol. 10, núm. 2, pp. 195-209.

Martín-Barbero, Jesús

1991 De los medios a las mediaciones. Comunicación, cultura y hegemonía, Gustavo Gili, México.

OBSERVATORIO DE LA DEMOCRACIA

2013 ¿Qué piensan los colombianos del proceso de paz? <http://www.obsdemocracia.org/ fileman / files / INFORMES\% 20COL / 2013 / Primera\% 2 OEncuesta\% 20 Nacional $\% 20$ sobre\%20el\%20Proceso\%20de\%20Paz.pdf>

Observatorio de Procesos de Desarme,

DESMOVILIZACIÓN Y REINTEGRACIÓN (ODDR)

2015 Actitudes democráticas en zonas de consolidación territorial, Universidad Nacional de Colombia/oDDR <http: / /obsdemocracia.org/>.

OROZCO, IVÁN

2003 "La postguerra colombiana: divagaciones sobre la venganza, la justicia y la reconciliación”, Working Paper, núm. 306, The Hellen Kellogg Institute for International Studies <https: / / kellogg.nd.edu / sites / default / files / old_files/documents/306_0.pdf>.

Rodríguez SALAZAR, TANIA

2003 "El debate de las representaciones sociales en la psicología social”, en Relaciones. vol. XXIV, núm. 93, pp. 52-80. 